\section{References}

APPLEBY, L. (1999) Safer Services. London: Department of Health.

original papers
BIERNAT, M. \& DOVIDIO, J. F. (2000) Stigma and stereotypes. InThe Social Psychology of Stigma (edsT. F. Heatherton, R. E. Kleck \& M. R. Hebel), pp. 88-125. NewYork: Guilford Press.

BYRNE, P. (2000) Stigma of mental illness and ways of diminishing it. Advances in Psychiatric Treatment, 6 $65-72$.

CORRIGAN, P., MARKOWITZ, F. E. WATSON, A., et al (2003) An attribution model of public discrimination towards people with mental illness. Journal of Health and Social Behaviour, 44, 162-179.

CRISP, A. H., GELDER, M. G., RIX, S., et al (2000) Stigmatisation of people with mental illnesses. British Journal of Psychiatry, 177, 4-7.

CUNNINGHAM, J. A., SOBELL, L. C. \& CHOW,V. M. C. (1993) What's in a label? The effects of substance types and labels on treatment considerations and stigma. Journal of Studies on Alcohol, 54,693-699.

DOCHERTY, J. B. (1997) Barriers to the diagnosis of depression in primary care. Journal of Clinical Psychiatry, 58, 5-10.

ERICKSON, P. G. \& GOODSTADT, M. S. (1993) Legal stigma for marijuana possession. Criminology, 17, 208-216.

KNOX,T., SMITH, J. \& HEREBY, H. (2003) Risk of suicide and related adverse outcomes after exposure to a suicide prevention programme in the US air force: cohort study. BMJ, 327, 13761378.

LINK, B. G., CULLEN, F.T., STRUENING, E. L., et al (1989) A modified labelling theory approach to mental disorder: an empirical assessment. American Sociological Review, 54, 400-423.

LINK, B. G., YANG, L. H., PHELAN, J. C., et al (2004) Measuring mental illness stigma. Schizophrenia Bulletin, 30, 511-541.
LUTY, J. S. \& GREWAL, P. (2002) A survey of British public's attitudes towards drug dependence. Journal of Substance Use, 7, 93-95.

OFFICE OF THE DEPUTY PRIME MINISTER (2004) Action on Mental Health - A Guide to Promoting Social Inclusion. http://www.socialexclusion.gov.uk/ page. asp? $\mathrm{id}=257$

\section{OPPENHEIM, A. N. (1992)}

Questionnaire, Design, Interviewing and Attitude Measurement. London: Continuum.

\section{PINFOLD, V., TOULMIN, H.,}

THORNICROFT G., et al (2003) Reducing psychiatric stigma and discrimination: evaluation of educational interventions in UK secondary schools. British Journal of Psychiatry, 182, 342-346.

RITSHER, J. B., OTILINGAM, P. G. \& GRAJALES, M. (2003) Internalized stigma of mental illness: psychometric properties of a new measure. Psychiatry Research, 121, 31-49.

STRUENING, E. L. \& COHEN, J. (1963) Factor invariance and other psychometric characteristics of five opinions about mental illness factors. Educational and Psychological Measurements, 23, 289-298. TAYLOR, S. M., DEAR, M. J. \& HALL, G. B. (1979) Attitudes towards the mentally ill and reactions to mental health facilities. Social Science and Medicine, 130, 281-290.

\footnotetext{
*Jason Luty Consultant in Addictions Psychiatry, TheTaylor Centre, Queensway House, Essex Street, Southend on Sea, Essex SS4 1RB, e-mail:

s1006h3607@blueyonder.co.uk, Daniel Fekadu Specialist Registrar in Child and Adolescent Psychiatry, Maudsley Hospital, London, Okon Umoh Locum Consultant in Child and Adolescent Psychiatry, Child and Family Service, Southend on Sea, Essex, John Gallagher Senior Lecturer in Nursing Studies, TheTaylor Centre, Southend on Sea, Essex
}

\title{
A survey of liaison psychiatry services in general hospitals and accident and emergency departments: do we have the balance right?
}

\section{AIMS AND METHOD}

By use of a telephone survey, we aimed to investigate liaison psychiatry services of all 29 general hospitals in Greater London. We specifically enquired about services to accident and emergency (A\&E) departments.

\author{
RESULTS \\ We identified wide variations in \\ staffing, working hours and patient \\ groups seen. Fourteen services (48\%) \\ worked over $24 \mathrm{~h}$ and $4(14 \%)$ had \\ specific $A \& E$ teams. Twelve services \\ $(41 \%)$ had established or planned \\ working links with community crisis \\ services.
}

\begin{abstract}
CLINICAL IMPLICATIONS
Generally staff numbers fell below national recommendations and there were frequent gaps in service provision. The recent focus on emergency care has lead to an increase in A\&E services, but there is a risk that liaison psychiatry services for other general hospital patients are being neglected.
\end{abstract}

Although the number of liaison psychiatry services in the UK is increasing, their development is idiosyncratic and services often fail to meet the recommendations of the Royal Colleges of Physicians \& Psychiatrists (2003). Across the UK there is a wide variation in staffing and service delivery (Howe et al, 2003; Ruddy \& House, 2003; Swift \& Guthrie, 2003).

Recent English health service initiatives have led to an increased focus on emergency mental healthcare, which potentially influences liaison psychiatry provision to accident and emergency (A\&E) departments. The Department of Health (2001) has recently set standards to reduce patients' attendance times in A\&E departments. In addition, the National Service Framework for Mental Health (Department of Health, 1999) has required specific services to be established for patients in crisis, many of who will attend A\&E departments. However, there is no optimum model of psychiatric service delivery to $A \& E$. Also, there is a risk that A\&E mental health services develop at the expense of other hospital departments.

As a city, London is unique in the UK in terms of its size, ethnic diversity and organisation of health services. As part of the establishment of a network of liaison psychiatry services in Greater London, we surveyed the current service provision to all the district general hospitals. We aimed to investigate the staffing and service provision of each service and to enquire about service developments, particularly with regard to $A \& E$ departments. 


\section{Method}

Greater London comprises the 32 London boroughs and the City of London. Using information supplied by the Department of Health, 29 Greater London district general hospitals with A\&E departments were identified. Information on bed numbers was obtained from hospital websites or directly from bed managers.

During the second quarter of 2004, a telephone survey was carried out using a predetermined list of questions. In each case, we tried to speak to a wellestablished member of the liaison psychiatry team. We enquired about the number of clinical team members and their professions. Specialist registrars ( $\mathrm{SpRs}$ ) in psychiatry were not included in these figures, as such posts are supernumerary and may not continue beyond the current trainee's attachment. We established details of service delivery. Hours of work were categorised into services operating within core 'working hours' (09.00 to $17.00 \mathrm{~h}$, Monday to Friday), those delivering an extended-hours service and those running $24 \mathrm{~h}$ per day. The survey enquired about specific patient groups seen and whether teams were funded and managed by a mental health or an acute trust. We also enquired whether the hospital had a mental health in-patient unit on site. Efforts were made to establish whether there were trends in service development by asking about recent service changes and teams' priorities for future development.

Data were analysed using the Statistical Package for the Social Sciences version 11.5 for Windows. Staffing levels were compared with the joint Royal College recommendations (Royal Colleges of Physicians \& Psychiatrists, 2003).

\section{Results}

Information was obtained from all 29 district general hospitals. Four hospitals had separate liaison psychiatry teams covering either A\&E or the rest of the hospital. In such instances, data from these two teams were combined in order to compare services between hospitals. Table 1 gives a profile of the different services and Table 2 summarises their staffing levels.

\section{Bed numbers}

The mean number of in-patient beds for the hospitals surveyed was 635 (range 257-1267, s.d.=228).

\section{Working hours}

Of the ten services working extended hours, seven included weekends and three operated on weekdays only.

\section{Staffing}

Overall, the size of teams varied between 1 and 25 whole-time equivalent staff ( $m e a n=8.2$, s.d. =5.9). Nine teams $(31 \%)$ consisted of nursing staff only. Ten services (34\%) had no dedicated consultant psychiatry sessions,
Table 1. Profile of 29 liaison psychiatry services in London

\begin{tabular}{lrl} 
& $\begin{array}{r}\text { Liaison psychiatry } \\
\text { services, } n(\%)\end{array}$ \\
\hline $\begin{array}{l}\text { Separate A\&E and in-patient services } \\
\text { Hours of service }\end{array}$ & $4 \quad(14)$ \\
Working hours (09.00 to 17.00 h) & $5 \quad(17)$ \\
Extended hours & $10(35)$ \\
24 h & $14 \quad(48)$ \\
Patient groups seen & & \\
A\&E & $29(100)$ \\
In-patients & $24 \quad(83)$ \\
Out-patients & $18(62)$ \\
Children and adolescents & $3 \quad(10)$ \\
Older adults & $19(66)$ \\
Alcohol and substance misuse & $23 \quad(80)$ \\
Self-harm & $29(100)$
\end{tabular}

A\&E, accident and emergency.

\section{Table 2. Staffing of $\mathbf{2 9}$ liaison psychiatry services in London ${ }^{1}$}

\begin{tabular}{|c|c|c|c|c|}
\hline \multirow[b]{2}{*}{ Hours of service } & \multicolumn{4}{|c|}{ Number of staff, mean (s.d.) } \\
\hline & Medical & Nursing & Other & Total \\
\hline $\begin{array}{l}\text { Working hours } \\
\qquad(n=5)\end{array}$ & $1.8(1.0)$ & $2.5(1.6)$ & $0.3(0.7)$ & $4.2(2.6)$ \\
\hline $\begin{array}{l}\text { Extended hours } \\
\qquad(n=10)\end{array}$ & $1.4(1.4)$ & $3.5(1.7)$ & $1.1(2.1)$ & $6.0(5.0)$ \\
\hline $24 \mathrm{~h}(n=14)$ & $1.7(2.0)$ & $8.8(4.9)$ & $0.8(1.3)$ & $11.3(5.9)$ \\
\hline
\end{tabular}

although these teams usually mentioned that they could contact a psychiatrist for advice.

\section{Patient groups}

All teams provided a service to their A\&E department and assessed patients following episodes of self-harm. Five services (17\%) operated in A\&E departments only. Patient groups seen are listed in Table 1.

\section{Services for older adults}

Nineteen services (66\%) accepted referrals of older adults, although 3 of these teams worked only in the A\&E department. Several teams mentioned that community psychiatry services for older adults visited the hospital to see patients. Four on-site liaison psychiatry services specifically for older adults were identified, for which limited data were collected. Each had a half-time consultant with one to two additional nursing or junior medical staff.

\section{Funding and management}

Twenty-five services (86\%) were managed by the mental health trust, $3(10 \%)$ by the acute trust and $1(3 \%)$ was 
jointly managed. Fifteen services (52\%) were funded by the mental health trust, 10 (35\%) were jointly funded and

original papers $4(14 \%)$ were funded by the acute trust.

\section{On-site psychiatric unit}

Eighteen district general hospitals (62\%) also had a psychiatric unit on site. There was a significant association between the presence of an on-site unit and the liaison psychiatry team delivering a $24-h$ service $\left(\chi^{2}=6.43\right.$, $P=0.01$ )

\section{Service developments}

Those teams providing extended and 24-h services generally reported that they had increased their hours of service during the previous 2 years. Three teams (10\%) reported that they also delivered the local mental health crisis or home treatment service. A further 9 services (31\%) reported plans to establish closer links between liaison psychiatry and community crisis services.

The most frequently cited priority for service development was for more staff, mentioned by 24 services $(83 \%)$. However, only 8 teams (28\%) had plans to expand. The second most common priority was for more accommodation, which was mentioned by 10 services (35\%).

\section{College recommendations}

The joint recommendations of the Royal Colleges of Physicians \& Psychiatrists (2003) for a liaison psychiatry service are based on a 09.00 to $17.00 \mathrm{~h}$ service in an average-sized district general hospital. Such a service should include one full-time consultant, a senior house officer, 5 nursing staff and 1-2 psychologists.

It is difficult to compare the recommendations with services delivering extended-hours and crisis services. However, only 13 teams (45\%) had a full-time equivalent consultant and 17 (59\%) had a full-time junior doctor. Only 14 services (48\%) had 5 or more full-time equivalent nursing staff; 13 of these delivered a $24-\mathrm{h}$ service and 1 an extended-hours service. Only 1 team had more than 1 full-time equivalent psychologist. Overall, only 1 extended-hours service had all of the recommended components.

\section{Discussion}

This is the first survey to investigate liaison psychiatry provision to London's district general hospitals. It identifies wide variations in staffing, hours of work and patient groups seen. All except one service fell short of the recommendations for service provision. However, there has been a recent expansion in services to $A \& E$ departments.

Many teams reported that changes in service provision to A\&E departments had occurred as a result of recent government targets. A minority of teams also delivered community crisis and home treatment services,

work that falls outside the generally accepted remit of a liaison psychiatry service and complicates the interpretation of the survey data.

The recent government targets for emergency mental health provision can be considered an opportunity to bring mental health resources into the district general hospitals. However, there is also a danger that the development of $A \& E$ services will be at the expense of services for other general hospital patients.

There is no recommended model for psychiatry service provision to A\&E departments. Further qualitative research might help to establish recommendations for A\&E services and how emergency mental health services in general should be delivered.

The London population has a number of characteristics that, although not unique among urban areas in the UK, contribute to relatively high levels of mental illness and an associated need for services (Mayor of London, 2003). These include large refugee and minority ethnic populations, high levels of homelessness and single occupancy households, and the fact that London contains many of the most deprived areas in the UK.

Compared with data from previous regional surveys in the UK (Howe et al, 2003; Ruddy \& House, 2003), a higher proportion of London district general hospitals had some form of liaison psychiatry service and a higher proportion of services had dedicated consultant psychiatry sessions. However, the combined picture is one of unmet need and a lack of rational planning of services.

\section{Limitations}

This study is likely to underestimate the provision of mental health services for general hospital patients, as a number of possible psychiatric and psychological services were not surveyed. Community psychiatric services for children, older adults and substance misuse may provide a consultation service to their local hospital. In addition, individual hospital departments may also employ therapists and psychologists to work with individual patient groups.

An underestimate of services may also have been a result of the omission of SpRs from the survey. Although SpRs are supernumerary and posts are not necessarily filled every year, where present SpRs make a significant contribution to service provision.

We compared each service with the recommendations for an average district general hospital. However, the needs for psychological services of individual hospitals will vary depending on bed numbers, the workload of the A\&E department and the epidemiology of the local population. The Colleges' recommendations also point out that larger teaching hospitals with tertiary referral centres will require a larger liaison psychiatry team, including at least two full-time consultant psychiatrists.

\section{Conclusions}

This survey describes the wide variety in liaison psychiatry provision to London's district general hospitals, with 
services generally falling below the recommended standards. Although the focus on A\&E provides an opportunity to increase liaison psychiatry services for one hospital department, there is a risk that the needs of other patient groups will be neglected. When services are planned the whole hospital should be considered to ensure that all patients receive comprehensive care.

\section{Declaration of interest}

None.

\section{Acknowledgements}

We thank Brendan McLoughlin and the London Development Centre for Mental Health who supported the study. We also thank all the liaison psychiatry staff who participated in this survey.

\section{References}

DEPARTMENT OF HEALTH (1999)

gov.uk/mayor/health/mentalhealth National Service Framework for Mental availability/mentalhealth_highlights.pdf Health: Modern Standards and Service Models. London: Department of Health.

ROYAL COLLEGE OF PHYSICIANS \& ROYAL COLLEGE OF PSYCHIATRISTS (2003) The Psychological Care of Medical Patients: A Practical Guide

DEPARTMENT OF HEALTH (2001)

Reforming Emergency Care: First Steps of a New Approach. London:

Department of Health.

HOWE, A., HENDRY, J. \& POTOKAR, J. (2003) A survey of liaison psychiatry services in the south-west of England. Psychiatric Bulletin, 27, 90-92.

MAYOR OF LONDON (2003) Availability of Mental Health Services in London. Highlights of a Report to the Mayor of London. London: Greater London Authority. http://www.london.

(Council Report CR108). London: Royal College of Physicians \& Royal College of Psychiatrists.

RUDDY, R. \& HOUSE, A. (2003) A standard liaison psychiatry service structure? A study of the liaison psychiatry services within six strategic health authorities. Psychiatric Bulletin, $27,457-460$.

SWIFT, G. \& GUTHRIE, E. (2003) Liaison psychiatry continues to expand: developing services in the British Isles. Psychiatric Bulletin, 27, 339-341.

Tamsin Kewley Specialist Registrar， *Jim Bolton Consultant Liaison Psychiatrist, Department of Liaison Psychiatry, St Helier Hospital, Wrythe Lane, Carshalton, Surrey SM5 1AA, e-mail: jim.Bolton@swlstg-tr.nhs.uk

\section{Knowledge of deep vein thrombosis among intravenous drug misusers}

\author{
AIMS AND METHOD
All patients attending the local \\ All patients attending the local \\ supervised drug consumption clinics \\ were surveyed over a month. \\ They were asked via a \\ questionnaire to list the risks \\ of injecting drugs, particularly \\ the symptoms and consequences \\ of deep vein thrombosis \\ (DVT). Of 69 patients \\ surveyed, 46 agreed to take \\ part.
}

Deep vein thrombosis (DVT) is a complication particularly associated with groin injecting in intravenous drug misuse (Roszler et al, 1989; Baldeweg, 2000; MacKenzie et al, 2000; McColl et al, 2001). There has been an increase in the numbers of drug misusers admitted to general hospitals in Gloucestershire with DVT, from 3 in 1998 to 20 in 2003. We suspect that this increase may be owing to an increased incidence of groin injecting. The large size of the groin vein makes it easy to locate, and it may be the last vein left when all others are impossible to use. It also has less of an impact on cosmetic appearance than other injection sites, and some users report a quicker/ better drug effect. Regular use of the groin site leads to a characteristic 'dimple' in the skin over the vein, making location of the site easier for the drug misuser. No survey or study of this type has been conducted in Gloucestershire before. Studies on the increased risk of DVT in the

\begin{abstract}
symptoms. The best informed were those who had experienced thrombosis themselves recently.

CLINICAL IMPLICATIONS

The results indicate an apparent lack of basic knowledge about the risks of DVT in this sample of drug misusers, and a need for some new initiatives to address health education in this area for all drug misusers.
\end{abstract}

original papers drug misuse population seem to have been mainly published in radiology or medical journals (Roszler et al, 1989; Baldeweg, 2000). Studies have focused on the medical outcomes or treatments available (MacKenzie et $a l, 2000)$. The issue of prevention of DVT has not generally been considered. When the prevention of drug misuse by injection is discussed in the literature it is most likely to concentrate on the spread of HIV (Williams et al, 1997) or other blood-borne viral infections.

\section{Method}

All patients attending the local supervised drug consumption clinics were surveyed over 1 month. All patients were opiate misusers currently on a replacement regime of methadone or buprenorphine requiring daily attendance. The only exclusion criterion was refusal by the patient. The participants were asked via a 